\title{
The Swiss Household Panel Study: Observing social change since 1999
}

\author{
Robin Tillmann Swiss Centre of Expertise in the Social Sciences FORS, Switzerland \\ robin.tillmann@fors.unil.ch \\ Marieke Voorpostel Swiss Centre of Expertise in the Social Sciences FORS, Switzerland \\ Erika Antal Swiss Centre of Expertise in the Social Sciences FORS, Switzerland \\ Ursina Kuhn \\ Swiss Centre of Expertise in the Social Sciences FORS, Switzerland \\ Florence Lebert Swiss Centre of Expertise in the Social Sciences FORS, Switzerland \\ Valérie-Anne Ryser Swiss Centre of Expertise in the Social Sciences FORS, Switzerland \\ Oliver Lipps Swiss Centre of Expertise in the Social Sciences FORS, Switzerland \\ Boris Wernli Swiss Centre of Expertise in the Social Sciences FORS, Switzerland
}

\section{Abstract}

Collecting data on households and individuals since 1999, the Swiss Household Panel (SHP) is an ongoing, unique, large-scale, nationally representative, longitudinal study in Switzerland ( $N=7,383$ households and $N=12,119$ persons interviewed in 2014). The data of the SHP provide a rich source of information to study social change in Switzerland over a significant period on a wide variety of topics. The SHP aims to provide both continuity and innovation in measurement and data collection, with the combination of retrospective and prospective longitudinal data in the most recent refreshment sample as one notable example of such an innovation. This paper provides an overview of the SHP - focusing on its origin, aims, design, content, data collection and adjustments, possibilities for cross-national comparisons, data use and accomplishments.

\section{Keywords}

Swiss Household Panel, household panel survey, design, longitudinal data

\section{Introduction}

The Swiss Household Panel (SHP) ${ }^{1}$ is a study of major importance in the Swiss social survey landscape. Collecting data on households and individuals since 1999, the SHP is a unique longitudinal study that allows for the analysis of mid- to long-term micro-social change on a wide variety of topics. Together with a few other nationally representative household panels from other nations, the SHP provides unique analytical opportunities to researchers in the social sciences. The SHP combines continuity with innovation. The majority of questions are asked annually, allowing for longitudinal analysis over a period now spanning 16 years. Additional research instruments, such as biographical questionnaires, provide an even longer-term context.

This paper provides an overview of the SHP. We focus first on its origin and aims. Next, we describe the SHP's design, questionnaire content, data 
collection, and data adjustments. Finally, we discuss possibilities for cross-national comparisons, data use, and accomplishments.

\section{Origin and aims}

The Swiss Priority Program "Switzerland Towards the Future" implemented the SHP as one of its key structural measures in 1999 (Budowski et al., 1998; Budowski et al., 2001; Joye \& Scherpenzeel, 1997). Experiences made from existing European panel surveys informed the SHP's design, notably the German Socio-Economic Panel (SOEP) (Schupp \& Wagner, 2007) and the British Household Panel Study (BHPS), which is now integrated into Understanding Society, the UK Household Longitudinal Survey (UKHLS) (Buck \& McFall, 2011).

Initially, the SHP was a joint project run by the Swiss National Science Foundation, the Swiss Federal Statistical Office, and the University of Neuchâtel. Between 2004 and 2007 the SHP developed a joint venture project "Living in Switzerland-2020" aimed at conducting a pilot study of the Statistics of Income and Living Conditions (CH-SILC) 2004-2005 survey in collaboration with the Swiss Federal Statistical Office. Since 2008, still funded by the Swiss National Science Foundation, the SHP has been integrated into the Swiss Centre of Expertise in the Social Sciences (FORS) hosted by the University of Lausanne.

Two main aims guide the SHP (Farago, 1996; Joye \& Scherpenzeel, 1997). The first is to ensure a solid database for social reporting on stability and changes in living arrangements and wellbeing in Switzerland to complement the data collected by the Swiss Federal Statistical Office. Indeed, the SHP is a unique longitudinal study, because it offers data to comprehensively analyse mid- to long-term micro-social change; other surveys in Switzerland offer a smaller range of topics, follow a restricted subgroup, or allow only the study of short-term transitions (Tillmann et al., 2012). It also aims to promote opportunities for quantitative social science research by making high-quality data available to Swiss social scientists and to the international social science research community.

Data collected from household panels not only allow for the estimation of gross transitions but also provide an understanding of those transitions, including the circumstances (family events, a change in the activity status, health events, etc.) causing movements in and out of a given state (for example, transitions into and out of poverty). The SHP is an important tool for fine-tuning our conceptions and analyses of social dynamics (Berthoud \& Gershuny, 2000; Budowski, et al., 2001; Rose, 1995) and changes across time (Menard, 2002).

The SHP features a broad range of fields and a variety of topics. This makes the SHP a valuable source of information for studies in different disciplines and allows for cross-domain analyses. To keep up with changes in the field, the SHP occasionally modifies the questionnaire and adds newly constructed variables to the dataset. A major criterion for any change to the questionnaire is that it should not compromise the comparability of the data over time. A second strong feature of the SHP is that all members of the households in the panel are interviewed. This allows for intra-household and intergenerational studies, such as the study of mutual influence of household members' attitudes and behaviours over time.

\section{Design \\ General design}

At present, the SHP comprises three samples: the SHP_I $(5,074$ households and 7,799 individuals interviewed first in 1999), the SHP_II (2,538 households and 3,654 individuals interviewed first 2004) and the SHP_III (3,989 households and 6,090 individuals interviewed first in 2013) (Voorpostel et al., 2014). See tables 3 and 4 for more details on the samples.

There are three types of questionnaires in the SHP: a household grid questionnaire to assess household composition, a household questionnaire, and an individual questionnaire. All household members aged 14 or older are eligible to answer the individual questionnaire. Each household has a reference person ${ }^{2}$ who completes the household grid and the household questionnaire. The household questionnaire includes in addition a proxy questionnaire on household members younger than 14 years, who are absent for the time of the field work, or who are unable to respond themselves due to illness or disability.

\section{Sampling procedure and follow-up procedure}

For the first sample of the SHP in 1999 (SHP_I), the Swiss Federal Statistical Office drew a random sample of private households on the basis of the 
Swiss telephone directory (SRH Stichprobenregister für Haushalterhebungen - the sampling frame for household surveys). At the time of the SHP_I sample's selection, the SRH's coverage rate was about $95 \%$. In order to compensate for selective nonresponse and attrition (e.g., deaths, hospitalisation, or migration) and to include new population groups, a random refreshment sample of households was added in 2004 (SHP_II) following the same sampling procedure. The sampling frame for SHP_II was CASTEM (Cadre de Sondage pour le Tirage d'Echantillons de Ménages), the follow-up to $\mathrm{SRH}$, that is owned by the Swiss Federal Statistical Office; CASTEM also represents a telephone directory. CASTEM covered about $92 \%$ of the Swiss private households at the time of SHP_II sampling. A second refreshment sample was added in 2013 (SHP_III). This sample was drawn from the SRPH (Stichprobenrahmen für die Personen- und Haushaltserhebungen), which consists of data coming from the cantonal and communal register of residents; the SRPH is owned by the Swiss Federal Statistical Office. As this sampling frame is on an individual basis, the selection units of the SHP_III were individuals rather than households. The complete households of the selected individuals were subsequently included in the sample. The SHP_III sample also was no longer restricted by the availability of landline telephone connections.

All three random samples are stratified by the seven major statistical regions of Switzerland. Within each major geographic region, each household (SHP_I and SHP_II) or individual (SHP_III) had the same inclusion probability, independent of the size of the household.

The SHP's reference population includes all private households whose members represent the non-institutional resident population in Switzerland. Individuals living in old peoples' homes, institutions, or prisons, are not part of the reference population.

\section{Follow-up procedure}

For the first sample, all households that were interviewed in the first wave (with at least the household questionnaire and one individual questionnaire completed) formed the initial panel to be followed over time. For the second and third samples, all households that completed at least the grid questionnaire in the first wave were approached again. Households that were not reached at all during the first wave or those that did not supply any information at the time of the first wave were not included in the panel in later waves. Households were no longer approached if they could not be contacted for seven waves, refused to participate any longer, moved away from Switzerland, or moved to an institution.

On the individual level, the SHP initially only followed original sample members ${ }^{3}$ (OSMs) from the first wave and their children; cohabitants ${ }^{4}$ were only (re-)interviewed as long as they lived with an OSM. Since 2007, cohabitants have also been followed and have been entered into the panel as a new household upon leaving the original household. As a general rule, OSMs are followed indefinitely until they leave the target population (e.g., in the case of death or institutionalisation).

\section{Survey content}

\section{Survey content overview}

The household and individual questionnaires cover a broad range of topics. ${ }^{5}$ They are also designed to collect both 'objective' data, such as financial resources, social position, and participation, and subjective data, such as satisfaction scores, values, and attitudes. The whole constitutes an operationalisation of different elements on the micro-social level: living conditions, life events, attitudes, perceptions, and lifestyles (Budowski, et al., 1998).

The questionnaire at the household level covers the following areas:

1. composition of the household: basic information (collected in the grid questionnaire) about all the members of the household, such as their age, sex, relations, nationality, level of education, and occupational status;

2. accommodation: the type and size of the accommodation, home ownership or tenancy, cost of and/or the subsidies received for housing, satisfaction with the accommodation, and evaluation of the state of the accommodation;

3. standard of living: possession of various goods such as cars, televisions or computers, and participation in various activities, such as holidays, meals at restaurants, or dentist visits, and the reasons (financial or otherwise) households do not have these goods or carry out these activities;

4. the household's financial situation: financial difficulties, indebtedness (and the reasons for 
it), total household income, payments to other households, expenses (e.g. for childcare), satisfaction with income, an estimate of the minimum income the household considers necessary, and an evaluation of how the household's financial situation has evolved;

5. the household and the family: external help available to the household for housework, childcare, or care for other household members, the division of housework and childcare, and decision-making within the household.

The individual questionnaires cover the following topics ${ }^{6}$ :

1. the household and the family: information on children living outside the household, time spent on housework, and satisfaction with private life and the share of housework;

2. health and quality of life: general illness and health problems, doctor and hospital visits, long-term handicaps, threats or attacks endured, self-perceived state of health, estimated evolution of the state of health, satisfaction with health and with life in general, feelings of safety, tobacco consumption, and physical activities;

3. social origin (asked at first interview only): information related to each respondent's parents, including profession, professional position, educational level, political positioning, nationality and any financial difficulties in the family of origin (at the reference age of 15);

4. education: the respondent's native language(s), level of education completed, education currently being pursued, and participation in on-the-job training;

5. employment: information on the respondent's profession, such as working conditions, number of hours worked, work schedule, atypical work, status in the labour market, previous jobs, job satisfaction, job insecurity, and personal qualifications;
6. income: total personal income, total professional income, social security pensions, social and private transfers, and other income, plus satisfaction with the financial situation and evaluation of changes in it;

7. participation, integration, and networks: frequency of social contacts, unremunerated work outside the home, participation in associations, membership of and participation in groups, assessment of social capital by means of evaluation of potential practical help and emotional support (from various social network ties) and general trust in people;

8. politics and values: political participation, membership, party identification, political positioning, satisfaction with the political system, evaluation of issues and political values;

9. leisure and media: leisure activities, amount of leisure and holiday time, use of media, and satisfaction with leisure and free time.

10. psychological scales: (from 2009 onwards) dimensions of self-perception (such as selfmastery and self-esteem) and other aspects like the Big Five personality traits.

Since the second wave, the questionnaire has also included a life events module assessing the occurrence of events such as the termination of relationships, deaths of family or friends, and conflicts with relatives; and an occupational calendar module assessing (on a monthly basis) the respondent's employment situation in the twelve months prior to the interview.

\section{Unique, annual, and rotating content}

In 2009 the SHP introduced a new system of modularization for the individual questionnaire. The SHP now contains three different types of questions: unique questions asked only once (usually in the first interview), core questions asked each wave and rotating core questions asked regularly (but not each year). Table 1 shows the different types of questions. 
Table 1: Questionnaire content

\begin{tabular}{|c|c|c|c|}
\hline Topics & Unique & Core & Rotating core \\
\hline Last job $^{*}$ & $x$ & & \\
\hline Social origin & $x$ & & \\
\hline Socio-demographics & & $x$ & \\
\hline Life events & & $x$ & \\
\hline Health & & $x$ & \\
\hline Education & & $x$ & \\
\hline Current job & & $x$ & \\
\hline Occupational calendar & & $x$ & \\
\hline Income & & $x$ & \\
\hline Social network & & & $x$ \\
\hline Leisure & & & $x$ \\
\hline Social participation & & & $x$ \\
\hline Politics & & & $x$ \\
\hline Religion & & & $x$ \\
\hline Psychological scales & & & $x$ \\
\hline
\end{tabular}

The rotating core questions are arranged in different modules, i.e. social network, religion, social participation, political behaviour and values, leisure and culture, and psychological scales. Table 2 shows the rotation calendar.

Table 2: Rotation calendar of the SHP modules from 2010 to 2020

\begin{tabular}{|c|c|c|c|c|c|c|c|c|c|c|c|}
\hline Module & 2010 & 2011 & 2012 & 2013 & 2014 & 2015 & 2016 & 2017 & 2018 & 2019 & 2020 \\
\hline Social network & $x$ & & & $x$ & & & $x$ & & & $x$ & \\
\hline Religion & & & $x$ & & & $x$ & & & $x$ & & \\
\hline Social participation & & $x$ & & & $x$ & & & $x$ & & & $x$ \\
\hline Political behaviour and values & & $x$ & & & $x$ & & & $x$ & & & $x$ \\
\hline Leisure and culture & $x$ & & & $x$ & & & $x$ & & & $x$ & \\
\hline Psychological scales & & & $x$ & & & $\mathrm{x}$ & & & $\mathrm{X}$ & & \\
\hline
\end{tabular}

\section{Life calendars}

The questionnaires used in the first wave of the SHP_III differed from those used in SHP_I and SHP_II. In the first wave of the SHP_III, retrospective individual biographical data were collected. In addition to the regular grid and the household questionnaire, respondents in the SHP_III sample completed a life calendar covering their entire life course starting from birth. The SHP_III life calendar is presented as a two-way grid on paper with the temporal dimension (in years) for the rows and various life domains in the columns. Respondents were asked to report events for each domain in this grid. This questionnaire has been developed with the NCCR LIVES, a Swiss National Centre of Competence dedicated to life course research. Thus, the SHP_III has an original design, combining retrospective biographical data with prospective longitudinal data.

The grid provides a visual structure which enhances memory retrieval (Berney \& Blane, 2003; Blane, 1996; Caspi et al., 1996). The SHP_III participants can visualize their life trajectories in all domains and can therefore link the occurrence and duration of events in different domains. Interrelatedness facilitates recall for distinct events because interrelated themes reflect individual autobiographical memories (Belli, 1998; Belli, Lee, 
Stafford, \& Chou, 2004). The visual structure also helps to detect gaps and inconsistencies. Overall, this method produces high-quality retrospective data (Freedman, Thornton, Camburn, Alwin, \& Young-DeMarco, 1988).

The life calendar covers the following domains of life:

1. residential trajectory: residential mobility;

2. residence permit: the different residence permits of non-Swiss respondents;

3. living arrangements: with whom the respondent lived during the life course;

4. partner relationships: partner relationships and changes in civil status;

5. family events: the occurrence and timing of family-related events such as births of children, parents' separation or divorce, and deaths of family members;

6. professional activities: professional activities and periods during which the respondent received social benefits;

7. health: the occurrence and duration of different health problems.

Retrospective data also exist on a subsample of the SHP_I respondents ( $n=5,560)$. In 2001-2002, all SHP_I respondents were approached by mail with a self-completion questionnaire. This questionnaire collected information on education, work, and family history.

\section{Data collection}

\section{Survey mode and interview length}

The panel survey is conducted annually from September to February by the institute M.I.S. Trend in Lausanne and Bern. Interviews are conducted in (Swiss) German, French, and Italian. The main mode of interviewing is computer-assisted telephone interviewing (CATI). Alternative modes were offered only in the first wave of the SHP_III sample; if no telephone number was available, respondents completed the household questionnaire by computer assisted personal interviewing (CAPI). The biographical questionnaire in the first wave of the SHP_III was self-administered or administered with an interviewer present. In addition to the alternative modes in the SHP_III, since 2010 (wave 12), CAPI and computer assisted web interview (CAWI) have been offered as alternative survey modes to those who initially refused to participate. ${ }^{7}$ The interviews require around 15 minutes to administer the grid and the household questionnaire and around 35 minutes to complete the individual questionnaires.

\section{Fieldwork and measures to increase response}

The fieldwork starts with sending a letter to the participating households informing them of the upcoming interviews. Enclosed with this letter, participants receive a newsletter containing some results of recent analyses of the SHP data. Since 2010, to enhance survey participation, each eligible respondent has received an unconditional incentive enclosed with the preliminary letter (a $20 \mathrm{CHF}$ voucher for a popular chain of supermarkets for the SHP_I and the SHP_II, and 10 CHF voucher for the SHP_III). ${ }^{8}$ Between wave 12 and wave 14, an additional incentive was offered to complete households for households of at least two eligible persons. This additional incentive (50 CHF) was given to the participants at the end of the fieldwork. For budgetary reasons the additional incentive was dropped in 2013.

To guarantee the smooth functioning of the fieldwork, M.I.S. Trend ensures a strict selection of only experienced interviewers who are native speakers. To increase the interviewers' motivation they can earn two collective bonuses. One bonus is based on the general response rate: all interviewers together have to complete at least $95 \%$ of the number of interviews carried out in the previous wave. The second bonus is geared towards interviewers who are engaged in refusal calls; it is based on the refusal conversion rate.

The SHP also invests significantly in refusal conversion, and makes great efforts to maintain contact with the households. Households that have not participated for at least one year are reapproached progressively. These households are sent a preliminary letter with the request to take part in the survey again. Only the most successful and specially trained interviewers are selected to contact these households. Households and individuals who refuse participation in the current wave are also re-contacted at a later point by interviewers trained in refusal conversion. This has resulted in a high refusal conversion rate; for example, about $45 \%$ of these households eventually participated in the survey in 2014.

\section{Panel maintenance}

To avoid households dropping out from the panel because of unsuccessful tracing (due to 
moving, changed phone numbers, household splits, etc.), several measures ensure that contact can be re-established with the respondents in later waves. In addition, a newsletter is enclosed with the advance letter at the start of each fieldwork phase, and respondents are asked to provide their mobile number and their e-mail address. If respondents are not willing to give this information or do not have a mobile number or e-mail address, they are asked to leave the address of an auxiliary (e.g., a family member living outside the household or a close friend) who can help in case of losing track of the respondent. Third, during the fieldwork period, households are called on different days of the week and at different times during the day in order to minimise non-contact. Fourth, a bilingual interviewer is responsible for relocating lost respondents. This interviewer tries to contact the respondent by mobile phone, e-mail, or through the auxiliary, searching different directories and registers to locate the respondent.

\section{Initial wave response and sample attrition}

At the household level, response rates were $64 \%$ in the first wave of the first sample (1999), $65 \%$ in the first wave of the second sample (2004), and $60 \%$ in the first wave of the third sample (2013). On the individual level, response rates (conditional upon household participation) were $85 \%, 76 \%$, and $81 \%$ respectively. Appendix A provides information on how the initial sample of SHP_III compared to the population distributions in 2013 on several characteristics ${ }^{9}$. The distribution in the sample is very close to that of to the general population, with a slight underrepresentation of those in the age category 25-34, men, and foreigners. The initial samples of the SHP also had a higher share of married individuals and a lower share of divorced individuals compared to the population.

Tables 3 and 4 show the number of households and individuals interviewed in every wave for the three samples. The tables show that sample sizes in the SHP, as in most panel studies, declined over time. After 16 waves of data collection, the number of households and individuals interviewed for the SHP_I corresponds to $55 \%$ of the initial number of households and $60 \%$ of the initial number of individuals interviewed. For the SHP_II, these figures are 55\% and 59\%, respectively, after 11 waves. SHP_III has only two waves, after which $81 \%$ of original households and $87 \%$ of original individuals remain.

Table 3: Number of households interviewed in SHP_I, SHP_II and SHP_III (1999-2014)

\begin{tabular}{ccccccccc}
\hline Year & Wave & $\begin{array}{c}\text { SHP_I } \\
\mathbf{n}\end{array}$ & $\begin{array}{c}\text { \% of } \\
\text { sample } \\
\text { size in } \\
\mathbf{1 9 9 9}\end{array}$ & $\begin{array}{c}\text { SHP_II } \\
\mathbf{n}\end{array}$ & $\begin{array}{c}\text { \% of } \\
\text { sample } \\
\text { size in } \\
\mathbf{2 0 0 4}\end{array}$ & $\begin{array}{c}\text { SHP_III } \\
\mathbf{n}\end{array}$ & $\begin{array}{c}\text { \% of } \\
\text { sample } \\
\text { size in } \\
\mathbf{2 0 1 3}\end{array}$ & $\begin{array}{c}\text { SHP_I+II } \\
+ \text { +III } \\
\mathbf{n}\end{array}$ \\
\hline 1999 & 1 & 5,074 & 100 & & & & & 5,074 \\
2000 & 2 & 4,425 & 87 & & & & & 4,425 \\
2001 & 3 & 4,139 & 82 & & & & & 4,139 \\
2002 & 4 & 3,582 & 71 & & & & & 3,582 \\
2003 & 5 & 3,227 & 64 & & & & & 3,227 \\
2004 & $6 / 1$ & 2,837 & 56 & 2,538 & 100 & & & 4,375 \\
2005 & $7 / 2$ & 2,457 & 48 & 1,799 & 71 & & & 4,256 \\
2006 & $8 / 3$ & 2,537 & 50 & 1,684 & 66 & & & 4,311 \\
2007 & $9 / 4$ & 2,817 & 56 & 1,494 & 58 & & & 4,264 \\
2008 & $10 / 5$ & 2,718 & 54 & 1,546 & 61 & & & 4,406 \\
2009 & $11 / 6$ & 2,930 & 58 & 1,476 & 58 & & & 4,542 \\
2010 & $12 / 7$ & 2,985 & 59 & 1,557 & 61 & & & 4,495 \\
2011 & $13 / 8$ & 2,977 & 59 & 1520 & 60 & & & 4,461 \\
2012 & $14 / 9$ & 2,968 & 58 & 1,493 & 59 & & & \\
2013 & $15 / 10 / 1$ & 2,881 & 57 & 1,488 & 57 & 3,989 & 100 & 8,358 \\
2014 & $16 / 11 / 2$ & 2,778 & 55 & 1,385 & 55 & 3,220 & 81 & 7,383 \\
\hline
\end{tabular}


Table 4: Number of persons interviewed in SHP_I, SHP_II and SHP_III (1999-2014)

\begin{tabular}{|c|c|c|c|c|c|c|c|c|}
\hline Year & Wave & $\begin{array}{c}\text { SHP_I } \\
n=\end{array}$ & $\begin{array}{c}\text { \% of } \\
\text { sample } \\
\text { size in } \\
1999\end{array}$ & $\begin{array}{c}\text { SHP_II } \\
\mathbf{n}=\end{array}$ & $\begin{array}{c}\% \text { of } \\
\text { sample } \\
\text { size in } \\
2004\end{array}$ & $\begin{array}{c}\text { SHP_III } \\
n=\end{array}$ & $\begin{array}{c}\text { \% of } \\
\text { sample } \\
\text { size in } \\
2013\end{array}$ & $\begin{array}{c}\text { SHP_I+II } \\
+ \text { III } \\
n=\end{array}$ \\
\hline 1999 & 1 & 7,799 & 100 & & & & & 7,799 \\
\hline 2000 & 2 & 7,073 & 91 & & & & & 7,073 \\
\hline 2001 & 3 & 6,601 & 85 & & & & & 6,601 \\
\hline 2002 & 4 & 5,700 & 73 & & & & & 5,700 \\
\hline 2003 & 5 & 5,220 & 67 & & & & & 5,220 \\
\hline 2004 & $6 / 1$ & 4,413 & 57 & 3,654 & 100 & & & 8,067 \\
\hline 2005 & $7 / 2$ & 3,888 & 50 & 2,649 & 72 & & & 6,537 \\
\hline 2006 & $8 / 3$ & 4’091 & 52 & 2,568 & 70 & & & 6,659 \\
\hline 2007 & $9 / 4$ & 4,630 & 59 & 2,350 & 64 & & & 6,980 \\
\hline 2008 & $10 / 5$ & 4,494 & 58 & 2,410 & 66 & & & 6,904 \\
\hline 2009 & $11 / 6$ & 4,800 & 62 & 2,309 & 63 & & & 7,109 \\
\hline 2010 & $12 / 7$ & 5,057 & 65 & 2,489 & 68 & & & 7,546 \\
\hline 2011 & $13 / 8$ & 5,103 & 65 & 2,481 & 68 & & & 7,584 \\
\hline 2012 & $14 / 9$ & 5,032 & 65 & 2,414 & 66 & & & 7,446 \\
\hline 2013 & $15 / 10 / 1$ & 4,880 & 63 & 2,327 & 64 & $6,090^{a}$ & 100 & 13,297 \\
\hline 2014 & $16 / 11 / 2$ & 4,678 & 60 & 2,150 & 59 & 5,291 & 87 & 12,119 \\
\hline
\end{tabular}

$\left.{ }^{a}\right)$ This number refers to the number of life calendars collected among respondents aged 16 and older.

The numbers in these tables reflect the number of observations in each wave, but do not give information on the respondents' longitudinal participation. Table 5 shows that respondents in SHP_I (on average) participated in 7.3 waves; on average the respondents in SHP_II and SHP_III responded in 5.5 and 1.6 waves, respectively. Table 5 also gives the number of respondents who participated in every wave ( $n=1,598$ in SHP_I, $n=957$ in SHP_II and $n=4,453$ in SHP_III). The table also shows that a significant number of participants are still being followed despite having missed some waves of observation. Finally, the table provides the number of respondents who have not been interviewed in the last three waves, suggesting the number of dropouts from the study $(5,404$ for SHP_I, and 2,129 for SHP_II) -although these respondents may still re-enter at a later point in time. 
Table 5: Characteristics of the SHP_I, SHP_II and SHP_III

\begin{tabular}{|c|c|c|c|}
\hline & SHP_I & SHP_II & SHP_III \\
\hline Households interviewed in first wave & 5,074 & 2,538 & 3,989 \\
\hline Individuals interviewed in first wave & 7,799 & 3,654 & 6,090 \\
\hline Years of data released & 1999-2014 & 2004-2014 & 2013-2015 \\
\hline Total number of waves currently available & 16 & 11 & 2 \\
\hline $\begin{array}{l}\text { Mean number of waves in which individual sample } \\
\text { members }^{a} \text { participated }\end{array}$ & 7.3 & 5.5 & 1.6 \\
\hline $\begin{array}{l}\text { Number of individuals who participated in all waves (fully } \\
\text { longitudinal respondents) }\end{array}$ & 1,598 & 957 & 4,453 \\
\hline $\begin{array}{l}\text { Number of individuals who participated in all waves for } \\
\text { which they were eligible }\end{array}$ & 2,470 & 1,287 & 4,590 \\
\hline $\begin{array}{l}\text { Number of individuals who missed at least one wave but } \\
\text { were present in one of the three most recent waves }\end{array}$ & 3,061 & 1,415 & $\mathrm{n} / \mathrm{a}$ \\
\hline $\begin{array}{l}\text { Number of individuals who did not participate in the last } \\
\text { three waves }\end{array}$ & 5,404 & 2129 & $\mathrm{n} / \mathrm{a}$ \\
\hline $\begin{array}{l}\text { Number of individuals known to be deceased, to be } \\
\text { institutionalized or to have emigrated }\end{array}$ & 536 & 187 & 23 \\
\hline
\end{tabular}

\footnotetext{
$\left.{ }^{a}\right)$ This percentage is based on all sample members who have participated at least once. Household members who never completed an individual questionnaire are not included.
}

Comparing the different response patterns (respondents who always participate, those who sometimes participate, and those who have not participated in the last three waves), dropouts and wave non-respondents are clearly somewhat selective (Voorpostel, 2010). As is found in other studies (Groves, 2006; Lillard \& Panis, 1998; Neukirch, 2002; Watson \& Wooden, 2009), SHP non-respondents are more likely to be younger, male, less educated, unemployed, and in poorer health; they are also less likely to be married or own a home (see Appendix C in the SHP Userguide, Voorpostel, et al., 2014). Nonetheless, these factors contribute only marginally to explaining response to the survey. For the most part, response seems random (Voorpostel, 2010).

\section{Data adjustments: Weighting and imputation}

It is essential to use weights in order to have estimates that are representative of the underlying population. The SHP provides several weights. First, weights are assigned to households and to individuals.
Second, a distinction is made between cross-sectional and longitudinal weights. Cross-sectional weights assure that the sample is representative for any given year of data collection and can be used for crosssectional analysis (for example, to calculate the percentage of households living in poverty or the population's general satisfaction with life in 2013). Longitudinal weights are meant for longitudinal analysis and refer to the first wave of the panel. These weights are used if respondents are followed over time from the first wave. These weights hence refer to the population in the first wave of a particular panel (1999, 2004, and 2013 for SHP_I, SHP_II, and SHP_III, respectively). For the SHP_II, for example, these weights should be used when conducting a longitudinal analysis starting in 2004 and continuing to any later wave (e.g., to study changes in general satisfaction with life). Both cross-sectional and longitudinal weights are assigned to individuals, but households are given only cross-sectional weights. ${ }^{10}$ For each of the type of weight, the SHP delivers two 
versions: one weight to obtain the size of the relevant Swiss population and one to maintain the sample size.

The weights are constructed in four steps. First, the inclusion probabilities are determined for every unit of the reference population, and then the inverse is taken as the initial weight. In a second step, the weights are adjusted for non-response, both in the initial wave and in later waves. The method used for modelling non-response is analysis by segmentation, as proposed by Kass (1980). Information on the nonrespondents comes from the official registers from which the samples were drawn, and from questionnaires completed in previous waves. ${ }^{11}$ To obtain weights for OSMs' cohabitants - whose inclusion probability is unknown - the generalised weight share method (GWSM) is used for the crosssectional individual weight and the household weight (Lavallée, 2002). The third step consists of combining the three panels using a factor allocating a relative importance to each of the samples based on its size. Finally, all weights are adjusted so that the estimated population sums are equal to the actual sums of the non-institutionalised Swiss population. In rare cases, Winsorisation (Hastings, Mosteller, Tukey, \& Winsor, $1947)$ is needed to correct for negative or extreme weights. ${ }^{12}$

As the longitudinal weights can only be used when analysing change since the first wave of any given panel, they are not suitable if the period analysed starts at a later wave. For the development of longitudinal samples that start after the first wave, transitional factors are provided. These transitional factors enable the researcher to create custom-made individual longitudinal weights over several consecutive waves. More information on the construction of these transitional factors, their applicability, and their limitations is available on the SHP homepage. Full documentation about the SHP's weighting scheme of the SHP can also be found on the SHP website.

\section{Data use}

SHP data are available free of charge. Users must sign a contract (available on the SHP website) and report the research topics for which they intend to use the SHP data. The currently registered SHP data users $(n=1,762)$ have reported a wide variety of topics.

Figure 1 shows the relative importance of the single topic categories given by the SHP data users. The category with the topics "Labour Market, Employment, Income" leads the table. "Poverty, Living Conditions, Quality of Life", "Health, Physical Activity" and "Life Course: Adolescence, Retirement, Aging" are also among the most frequently listed topics. Moreover, around 300 users mentioned using the data for seminars and courses.

\section{Figure 1: Areas of interest mentioned by SHP data users}

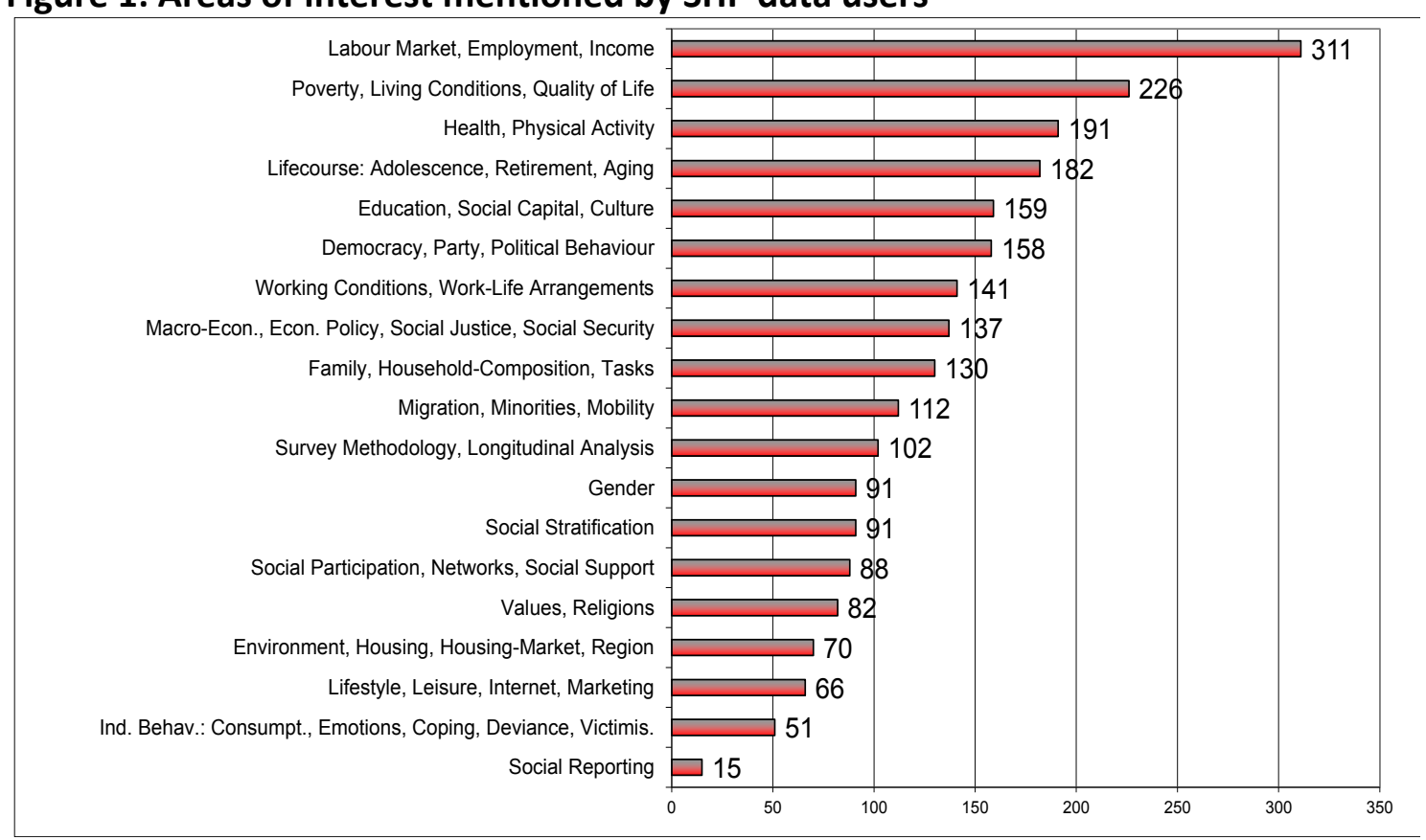


The value of the SHP as a tool to investigate social change is also demonstrated in the large number of publications in various disciplines that have been based on the data. These studies have addressed a wide variety of topics, including changes in wellbeing following major life events (Anusic, Yap, \& Lucas, 2014); changes in social contacts over the life course (Kalmijn, 2012); mutual influence between mothers, fathers and children with respect to support for political parties (Fitzgerald, 2011); the impact of parental divorce on political and civic participation (Voorpostel \& Coffé, 2014); the relation between conspicuous consumption in the neighbourhood and income satisfaction (Winkelmann, 2012); and the determinants of change in physical activity levels in young adults (Zimmermann-Sloutskis, Wanner, Zimmermann, \& Martin, 2010). The SHP has also featured in many cross-national comparative studies. Examples include studies on the causal connection between civic engagement and generalised trust in several countries (van Ingen \& Bekkers, 2015); the stability of political interest over time in different countries (Prior, 2010); the relationship between unemployment and wellbeing in Germany and Switzerland (Oesch \& Lipps, 2012); and the impact of political discord in the family on engagement in politics in Switzerland, Germany, and the UK (Fitzgerald \& Curtis, 2012). ${ }^{13}$

\section{International comparison}

The SHP was designed to allow cross-national comparisons with other household studies. In 2008 the SHP was included in the Cross-National Equivalent File (CNEF), which provides harmonized data from several household studies. To date the CNEF comprises the German SOEP, the BHPS, the US Panel Study of Income Dynamics (PSID), the Canadian Survey of Labour and Income Dynamics (SLID), the Household Income and Labour Dynamics in Australia (HILDA), the Korean Labor and Income Panel Study (KLIPS) and the Russia Longitudinal Monitoring Survey (RLMS-HSE) (Frick, Jenkins, Lillard, Lipps, \& Wooden, 2007). The CNEF covers the following main topics: demographics, employment, income, and health. ${ }^{14}$
Moreover, the SHP contains variables in various domains that can be compared to other panels, such as political behaviour and values (for example, the left-right self-placement scale, interest in politics, participation in polls, and general trust in people), social participation (for example, participation in sport/leisure associations, unions, political parties or charitable organisations), leisure and culture (different items broadly comparable with those of the SOEP and the UKHLS), religion (with usual questions on religious affiliation and participation in religious services), and psychological scales (for example, the Big Five personality traits, the Morally Debatable Behaviour Scale, satisfaction scales, and sense of control). In addition, the SHP provides internationally comparable constructed variables for research in social stratification in particular (such as Treiman's prestige scale or the European Socio-Economic Classification (ESeC)).

\section{Conclusion}

This paper described the main aspects of the SHP and analysed how it is distinctive as a long-term longitudinal survey. The SHP has been collecting high-quality data on Swiss households for 16 years, and it has good prospects to continue for many more years to come. With 16 years of observation, the SHP is an extremely valuable source of data for researchers in the social sciences in Switzerland and abroad. The SHP aims to provide both continuity and innovation in measurement and data collection. One notable innovation was the design of the SHP_III, which combined retrospective and prospective longitudinal data.

The importance of the SHP for the research community is borne out by its large number of active data users, who have contributed to an impressive list of publications based on the SHP data, covering a very broad spectrum of research domains. This is a strong indication that the multidisciplinary SHP survey serves the research needs of a diverse and interdisciplinary academic community, both nationally and internationally.

\section{Acknowledgements}

The Swiss Household Panel (SHP) is based at the Swiss Centre of Expertise in the Social Sciences (FORS). The project is supported by the Swiss National Science Foundation. 


\section{References}

Anusic, I., Yap, S. Y., \& Lucas, R. (2014). Testing set-point theory in a Swiss national sample: Reaction and adaptation to major life events. Social Indicators Research, 119(3), 1265-1288. http://dx.doi.org/10.1007/s11205-013-0541-2

Belli, R. F. (1998). The structure of autobiographical memory and the event history calendar: Potential improvements in the quality of retrospective reports in surveys. Memory, 6(4), 383-406. http://dx.doi.org/10.1080/741942610

Belli, R. F., Lee, E. H., Stafford, F. P., \& Chou, C.-H. (2004). Calendar and question-list survey methods: Association between interviewer behaviors and data quality. Journal of Official Statistics, 20(2), 185.

Berney, L., \& Blane, D. (2003). The life grid method of collecting retrospective information from people at older ages. Research Policy and Planning, 21(2), 13-22.

Berthoud, R., \& Gershuny, J. (2000). Seven years in the lives of British families: Evidence on the dynamics of social change from the British Household Panel Survey: Policy Press.

Blane, D. B. (1996). Collecting retrospective data: development of a reliable method and a pilot study of its use. Social science \& medicine, 42(5), 751-757. http://dx.doi.org/10.1016/0277-9536(95)00340-1

Buck, N., \& McFall, S. (2011). Understanding Society: design overview. Longitudinal and Life Course Studies, 3(1), 5-17.

Budowski, M., Niklowitz, M., Scherpenzeel, A., Tillmann, R., Wernli, B., \& Zimmermann, E. (1998). Aims and architecture of the Swiss Household Panel. Neuchatel: Swiss Household Panel.

Budowski, M., Tillmann, R., Zimmermann, E., Wernli, B., Scherpenzeel, A., \& Gabadinho, A. (2001). The Swiss Household Panel 1999-2003: Data for research on micro-social change. ZUMA-Nachrichten, 50, 100125.

Caspi, A., Moffitt, T. E., Thornton, A., Freedman, D., Amell, J. W., Harrington, H., Smeijers, J., \& Silva, P. A. (1996). The life history calendar: A research and clinical assessment method for collecting retrospective event-history data. International Journal of Methods in Psychiatric Research, 6, 101114. http://dx.doi.org/10.1002/(SICI)1234-988X(199607)6:2<101::AID-MPR156>3.3.CO;2-E

Farago, P. (1996). Gesellschaftliche dauerbeobachtung im SP "Zukunft Schweiz/Demain la Suisse" [Swiss Priority Programme "Switzerland towards the future"]. Bern: Swiss National Science Foundation.

Fitzgerald, J. (2011). Family dynamics and Swiss parties on the rise: Exploring party support in a changing electoral context. The Journal of Politics, 73(3), 783-796. http://dx.doi.org/10.1017/S0022381611000454

Fitzgerald, J., \& Curtis, K. A. (2012). Partisan discord in the family and political engagement: A comparative behavioral analysis. The Journal of Politics, 74(01), 129-141. http://dx.doi.org/10.1017/S0022381611001150

Freedman, D., Thornton, A., Camburn, D., Alwin, D., \& Young-DeMarco, L. (1988). The life history calendar: A technique for collecting retrospective data. Sociological methodology, 18(1), 37-68. http://dx.doi.org/10.2307/271044

Frick, J. R., Jenkins, S. P., Lillard, D. R., Lipps, O., \& Wooden, M. (2007). The Cross-National Equivalent File (CNEF) and its member country household panel studies. Schmollers Jahrbuch, 127, 627-654.

Groves, R. M. (2006). Nonresponse rates and nonresponse bias in household surveys. Public Opinion Quarterly, 70(5), 646-675. http://dx.doi.org/10.1093/poq/nfl033

Hastings, C., Mosteller, F., Tukey, J. W., \& Winsor, C. P. (1947). Low Moments for Small Samples: A Comparative Study of Order Statistics. The Annals of Mathematical Statistics, 18(3), 413-426. http://dx.doi.org/10.1214/aoms/1177730388

Joye, D., \& Scherpenzeel, A. (1997). Observation à long terme: Projet de panel. Pro-gramme Prioritaire Demain la Suisse. Bern: Swiss National Science Foundation.

Kalmijn, M. (2012). Longitudinal analyses of the effects of age, marriage, and parenthood on social contacts and support. Advances in Life Course Research, 17(4), 177-190. http://dx.doi.org/10.1016/j.alcr.2012.08.002

Kass, G. (1980). An exploratory technique for investigating large quantities of categorical data. Applied Statistics, 29(2), 119-127. http://dx.doi.org/10.2307/2986296 
Lavallée, P. (2002). Le sondage indirect ou la méthode généralisée du partage des poids. Paris: Ellipses.

Lillard, L. A., \& Panis, C. W. A. (1998). Panel attrition from the Panel Study of Income Dynamics: Household income, marital status, and mortality. Journal of Human Resources, 13(2), 437-457. http://dx.doi.org/10.2307/146436

Menard, S. (2002). Longitudinal research. Thousand Oaks: Sage.

Neukirch, T. (2002). Nonignorable attrition and selectivity biases in the Finnish subsample of the ECHP: An empirical study using additional register information. Chintex Working Paper \#5. Frankfurt-am-Main: J.W. Goethe-Universität.

Oesch, D., \& Lipps, O. (2012). Does unemployment hurt less if there is more of it around? A panel analysis of life satisfaction in Germany and Switzerland. European Sociological Review, 29(5), 955-967. http://dx.doi.org/10.1093/esr/jcs071

Prior, M. (2010). You've either got it or you don't? The stability of political interest over the life cycle. The Journal of Politics, 72(03), 747-766. http://dx.doi.org/10.1017/\$0022381610000149

Rose, D. (1995). Household panel studies: An overview. Innovation: The European Journal of Social Science Research, 8(1), 7-24. http://dx.doi.org/10.1080/13511610.1995.9968428

Schupp, J., \& Wagner, G. (2007). The German Socio-Economic Panel Study (SOEP): Scope, evolution and enhancements. Schmollers Jahrbuch, 127(1), 139-169.

Tillmann, R., Voorpostel, M., Bloch, D., Kuhn, U., Lebert, F., Rothenbühler, M., Ryser, V.-A., Schmid, F., \& Wernli, B. (2012). Swiss Household Panel : Scientific Report 2011. Lausanne: FORS.

van Ingen, E., \& Bekkers, R. (2015). Generalized trust through civic engagement? Evidence from five national panel studies. Political Psychology, 36(3), 277-294. http://dx.doi.org/10.1111/pops.12105

Voorpostel, M. (2010). Attrition in the Swiss Household Panel by demographic characteristics and levels of social involvement. Swiss Journal of Sociology, 36(2), 359-377.

Voorpostel, M., \& Ryser, V.-A. (2011). Mixed mode data collection as a strategy to decrease panel attrition in the Swiss Household Panel. Lausanne: FORS.

Voorpostel, M., \& Coffé, H. (2014). The effect of parental separation on young adults' political and civic participation. Social Indicators Research, 124(1), 295-316. http://dx.doi.org/10.1007/s11205-0140770-z

Voorpostel, M., Tillmann, R., Lebert, F., Kuhn, U., Lipps, O., Ryser, V.-A., Schmid, F., Antal, E., \& Wernli, B. (2014). Swiss Household Panel User Guide (1999-2013), Wave 15. Lausanne: FORS.

Watson, N., \& Wooden, M. (2009). Identifying factors affecting longitudinal survey response. In P. Lynn (Ed.), Methodology of longitudinal surveys (pp. 157-182). London: Wiley. http://dx.doi.org/10.1002/9780470743874.ch10

Winkelmann, R. (2012). Conspicuous consumption and satisfaction. Journal of Economic Psychology, 33(1), 183-191. http://dx.doi.org/10.1016/j.joep.2011.08.013

Zimmermann-Sloutskis, D., Wanner, M., Zimmermann, E., \& Martin, B. W. (2010). Physical activity levels and determinants of change in young adults: a longitudinal panel study. International Journal of Behavioral Nutrition and Physical Activity, 7(2), 1-13. http://dx.doi.org/10.1186/1479-5868-7-2 


\section{Appendix A}

\section{Table A.1: Representativeness of the SHP_III distributions in 2013}

\begin{tabular}{|c|c|c|}
\hline Age & Population & SHP_III \\
\hline 14-19 & $7.46 \%$ & $8.99 \%$ \\
\hline $20-24$ & $6.87 \%$ & $6.97 \%$ \\
\hline $25-34$ & $15.98 \%$ & $11.61 \%$ \\
\hline $35-44$ & $17.09 \%$ & $16.96 \%$ \\
\hline $45-54$ & $18.74 \%$ & $19.49 \%$ \\
\hline $55-64$ & $14.34 \%$ & $14.94 \%$ \\
\hline \multirow[t]{2}{*}{$65-$} & $19.53 \%$ & $21.06 \%$ \\
\hline & $100.00 \%$ & $100.00 \%$ \\
\hline \multicolumn{3}{|l|}{ Gender } \\
\hline Male & $49.64 \%$ & $48.92 \%$ \\
\hline \multirow[t]{2}{*}{ Female } & $50.36 \%$ & $51.08 \%$ \\
\hline & $100.00 \%$ & $100.00 \%$ \\
\hline \multicolumn{3}{|l|}{ Swiss nationality } \\
\hline Swiss & $75.84 \%$ & $82.51 \%$ \\
\hline \multirow[t]{2}{*}{ Foreigner } & $24.17 \%$ & $17.49 \%$ \\
\hline & $100.00 \%$ & $100.00 \%$ \\
\hline \multicolumn{3}{|l|}{ Region } \\
\hline Geneva, Vaud, Valais & $18.80 \%$ & $18.46 \%$ \\
\hline Bern, Fribourg, Jura, Neuchâtel, Solothurn & $22.20 \%$ & $23.20 \%$ \\
\hline Aargau, Basel-Landschaft, Basel-Stadt & $13.63 \%$ & $13.51 \%$ \\
\hline Zürich & $17.89 \%$ & $16.01 \%$ \\
\hline $\begin{array}{l}\text { Appenzell Ausserrhoden, Appenzell Innerrhoden, Glarus, } \\
\text { Graubünden, Schaffhausen, St. Gallen, Thurgau }\end{array}$ & $13.82 \%$ & $14.26 \%$ \\
\hline Luzern, Nidwalden, Obwalden, Schwyz, Uri, Zug & $9.38 \%$ & $10.24 \%$ \\
\hline \multirow[t]{2}{*}{ Ticino } & $4.29 \%$ & $4.30 \%$ \\
\hline & $100.00 \%$ & $100.00 \%$ \\
\hline \multicolumn{3}{|l|}{ Civil status } \\
\hline Single & $43.08 \%$ & $43.19 \%$ \\
\hline Married & $44.79 \%$ & $46.67 \%$ \\
\hline Widower & $4.36 \%$ & $3.63 \%$ \\
\hline \multirow[t]{2}{*}{ Divorced } & $7.77 \%$ & $6.51 \%$ \\
\hline & $100.00 \%$ & $100.00 \%$ \\
\hline
\end{tabular}




\section{Endnotes}

${ }^{1}$ www.swisspanel.ch

$261 \%$ of the reference persons in 2013 were female. Among households including couples this was $58 \%$.

${ }^{3}$ These include all eligible household members living in the selected households in the first wave (in 1999, 2004 or 2013).

${ }^{4}$ Cohabitants are persons who entered the selected households after the first wave, and who are not children of any OSM.

${ }^{5}$ Questionnaires can be searched online, and are also available in pdf format.

${ }^{6}$ The first wave of the SHP_III did not include an individual questionnaire. The first time an individual questionnaire was administered was in Wave 2 (2014). In Wave 1 in addition to the grid and household questionnaire, respondents completed a biographical questionnaire (see the Life calendars section).

${ }^{7}$ In 2010, the SHP tested these alternative modes of data collection (CAPI and CAWI) among initial refusals as a first step toward a potential mixed-modes strategy of data collection. An evaluation of this mixed-mode approach showed that it is not useful and even risky, at least in terms of participation, to implement a full mixed-modes system of data collection for the SHP survey (see Voorpostel and Ryser, 2011).

${ }^{8}$ The incentive for the SHP_III is lower for budgetary reasons only. Between wave 8 and wave 12 participants received a conditional incentive after completion of the individual questionnaire; before wave 8 there were no incentives.

${ }^{9}$ The distributions of the initial samples of the SHP_I and SHP_II were comparable. For more detailed information on representativeness and weight construction of the SHP_I and SHP_II samples, full documentation can be found here and here.

${ }^{10}$ Because the household composition changes over time, it does not make sense to assign them longitudinal weights.

${ }^{11}$ In addition, at the first wave of the SHP_II and SHP_III a non-response survey (PAPI) was sent to all the households who could not be contacted or who refused to participate.

${ }^{12}$ This procedure is used to replace extreme values by the values at the first and the $99^{\text {th }}$ percentile of the weight distribution.

${ }^{13}$ A complete list of publications based on the SHP can be found here.

${ }^{14}$ See the variable list and availability for each country file at http://cnef.ehe.osu.edu/files/2012/11/CNEF_codebooks_All.pdf. 